\title{
Um dispositivo analítico para a investigação da leitura de textos de divulgação científica
}

Ricardo Henrique Almeida Dias

Jornalista, mestre em educação pela Faculdade de Educação - Universidade Estadual de Campinas. Membro do Grupo de Estudos e Pesquisa em Ciência e Ensino*.

E-mail: rhad@mail.com

Maria José P. M. de Almeida

Professora titular na área de Metodologia de Ensino: Física na Faculdade de Educação Universidade Estadual de Campinas. Coordenadora do Grupo de Estudos e Pesquisa em Ciência e Ensino**.

E-mail:mjpma@unicamp.br

Resumo: Propomos um dispositivo analítico de leituras de divulgação científica. Levantamos algumas características do discurso jornalístico, com base nos critérios de noticiabilidade, bem como algumas especificidades do jornalismo científico para a construção de um dispositivo analítico para leitura de textos de divulgação científica sobre física, nas revistas Ciência Hoje e Pesquisa Fapesp. Esse dispositivo foi colocado a funcionar em uma atividade de leitura com estudantes do curso de licenciatura em física. A análise de respostas a um questionário e de falas gravadas dos estudantes indicou alguns de seus gestos de interpretação com características do discurso jornalístico, o que contribuiu para justificar a construção do dispositivo.

Palavras-chave: Leitura, análise de discurso, divulgação científica, critérios de noticiabilidade.
Abstract: We propose an analytical device for reading of scientific popularization. We specify some characteristics of journalistic discourse, based on the newsworthiness and scientific journalism for the construction of an analytical device for analysis of reading scientific popularization texts about physics in the magazines Ciência Hoje and Pesquisa Fapesp. This device was put in place during a reading activity with undergraduate students of physics. The analysis showed specificities of journalistic discourse on their interpretations, which justify the elaboration of the device.

Keywords: Reading, discourse analysis, scientific popularization, newsworthiness

O modo como circulam conhecimentos científicos e tecnológicos em um âmbito mais amplo do que o restrito campo científico, no que conhecemos por divulgação científica, já foi objeto de estudo de diversas linhas de pesquisa, tais como a linguística, a comunicação, a educação em ciências, entre outras áreas 
do saber. Alguns trabalhos desenvolvidos no Grupo de Estudos e Pesquisa em Ciência e Ensino da FE/Unicamp se preocuparam especialmente com questões concernentes a aspectos da leitura de textos de divulgação científica em situações específicas de ensino.

Com base nesses trabalhos, e buscando a contribuição do conhecimento jornalístico, neste artigo nos debruçamos sobre a construção de um dispositivo analítico para a investigação de aspectos da leitura de textos de jornalismo científico e expomos exemplos obtidos em uma atividade de leitura com licenciandos em física. A construção desse dispositivo, a partir de conhecimentos já levantados sobre o jornalismo e o jornalismo científico, se justifica dada a natureza dos textos de divulgação escolhidos - textos sobre física nas revistas Ciência Hoje e Pesquisa Fapesp, publicações com algum destaque no campo do jornalismo científico.

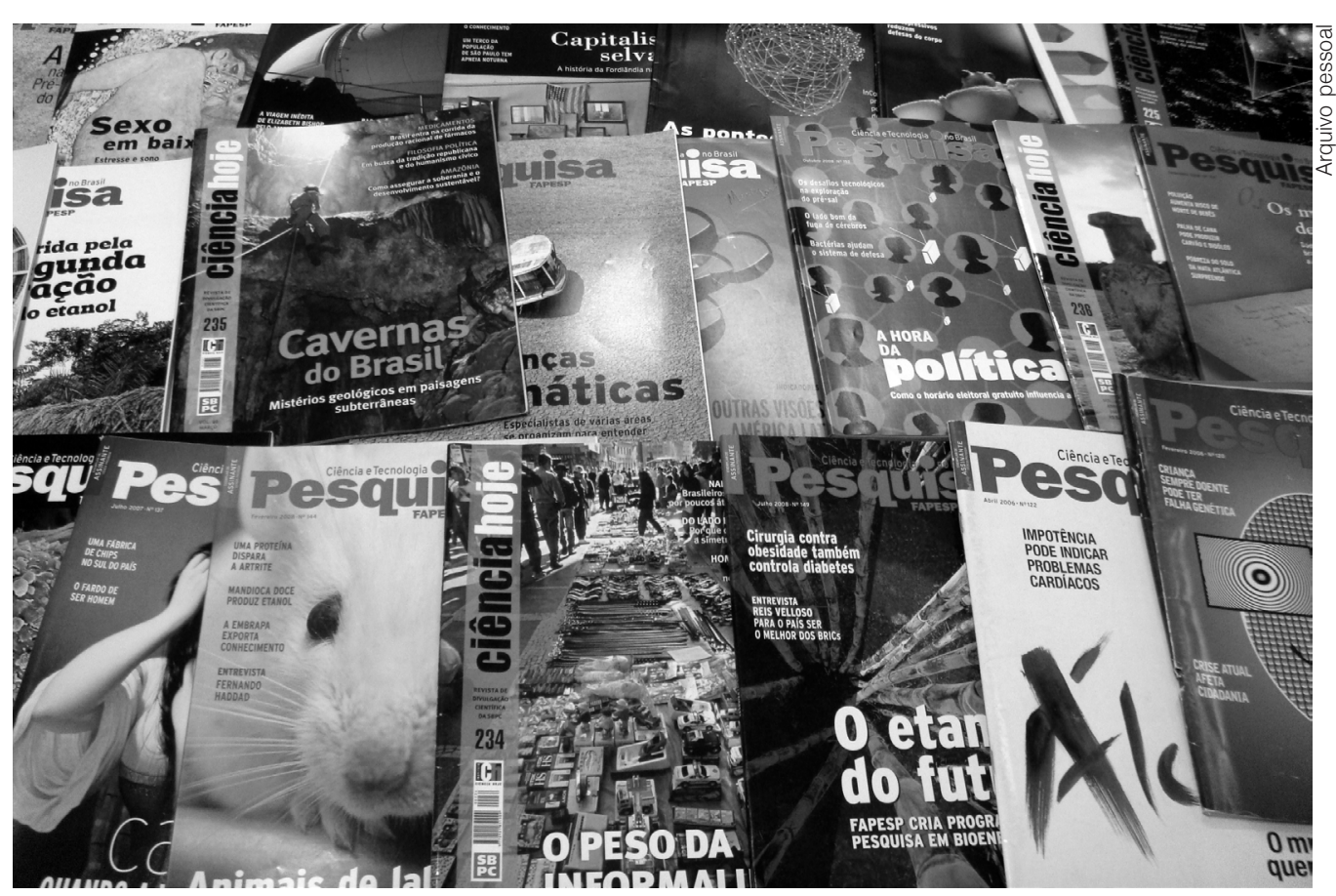

Divulgação científica e novos mecanismos de leitura: contribuições para o jornalismo científico.

\section{APOIO TEÓRICO E METODOLÓGICO}

Como apoio teórico para inserção numa atividade envolvendo a leitura de textos de divulgação científica e construção de um dispositivo analítico, utilizamos a vertente da análise de discurso originada na década de 1960, na França, por Michel Pêcheux, principalmente com apoio em textos produzidos no Brasil por Eni Orlandi. Esse referencial pareceu-nos adequado por considerar que a linguagem não é transparente, bem como admitir que a relação entre homem, pensamento e mundo não acontece de forma direta, e sim mediada. Para os escopos desta investigação julgamos necessário destinar uma atenção especial 
às considerações da análise de discurso sobre a posição que o analista assume para realizar seu trabalho. Para Almeida, em qualquer estudo a explicitação do dispositivo teórico colocado a funcionar é fundamental e quase sempre seu papel vai além daquilo que frequentemente é suposto pelos autores do estudo, sendo que o suporte teórico não entra em cena apenas na análise de informações obtidas com a intenção de se solucionar um problema, pois "as conviç̧ões que esse referencial possibilita já se fazem presentes na definição desse problema. Por outro lado, a construção de um dispositivo analítico vai além do simples uso do referencial teórico e está associada à natureza do problema a ser analisado". Para Orlandi, o dispositivo analítico tem como característica colocar o dito em relação ao não dito. O que o sujeito diz em um lugar com o que é dito em outro lugar, "o que é dito de um modo com o que é dito de outro, procurando ouvir, naquilo que o sujeito diz, aquilo que ele não diz mas que constitui igualmente os sentidos de suas palavras"2.

Assim, construímos um dispositivo analítico composto de conhecimentos já sistematizados sobre o jornalismo, como os critérios de noticiabilidade e algumas especificidades da linguagem do jornalismo científico. Neste artigo expomos uma análise de leitura de textos de jornalismo científico por licenciandos em física, que levou em consideração o dispositivo construído.

\section{CRITÉRIOS DE NOTICIABILIDADE}

Para auxiliar-nos no levantamento de algumas características do discurso jornalístico, tendo por objetivo a construção de um dispositivo analítico para a leitura de textos de divulgação, julgamos ser conveniente abordar as condições em que determinado assunto teria que se encaixar para se tornar notícia. Para Traquina, uma conclusão geral dos estudos sobre os conteúdos dos meios noticiosos é que as notícias apresentam um padrão geral estável e previsível:

A previsibilidade do esquema geral das notícias deve-se à existência de critérios de noticiabilidade, isto é, à existência de valores-notícia que os membros da tribo jornalística partilham. Podemos definir o conceito de noticiabilidade como o conjunto de critérios e operações que fornecem a aptidão de merecer um tratamento jornalístico, isto é, possuir valor como notícia ${ }^{3}$.

Para Wolf ${ }^{4}$, a noticiabilidade é constituída pelo conjunto de requisitos que se exigem dos acontecimentos para adquirirem a existência pública de notícias. Em uma seleção dos critérios dos valores-notícia, Traquina seleciona: a morte; a notoriedade do ator principal do acontecimento; a proximidade, sobretudo em termos geográficos, mas também em termos culturais; a relevância; a novidade; o tempo; a notabilidade; o inesperado, que seria a notícia que irrompe e surpreende a expectativa da comunidade jornalística; o conflito ou controvérsia; a infração e o escândalo.

Apesar de abordarmos algumas noções sobre critérios de noticiabilidade, ressaltamos que estes não possuem existência intrínseca, pois estão de alguma
1. ALMEIDA, M. J. P. M. de. Discursos da ciência e da escola: ideologia e leituras possíveis. Campinas: Mercado de Letras, 2004. p. 44.

2. ORLANDI, E. P. Análise de discurso: princípios e procedimentos. Campinas: Pontes, 2005. p. 59.

3. TRAQUINA, N. Teorias do jornalismo: a tribo jornalística - uma comunidade interpretativa transnacional. Florianópolis: Insular, 2005. p. 63.

4. WOLF, M. Teorias da comunicação. Lisboa: Presença, 2006. p. 190. 
forma remetidos aos aspectos políticos da produção jornalística, como podemos considerar em alguns trabalhos que se detiveram em aspectos políticos e ideológicos na práxis jornalística. Marcondes Filho debruça-se sobre as questões ideológicas - no sentido marxista do termo - e sociais da prática jornalística. Para o autor, atuar no jornalismo é uma opção ideológica, ou seja, definir o que vai sair, como, com que destaque e com que favorecimento, corresponde a um ato de seleção e de exclusão.

Este processo é realizado segundo diversos critérios, que tornam o jornal um veículo de reprodução parcial da realidade. Definir a notícia, escolher a angulação, a manchete, a posição na página ou simplesmente não dá-la é um ato de decisão consciente dos próprios jornalistas. É sobre a notícia que se centra o interesse principal no jornalismo ${ }^{5}$.

Levando-se em consideração a dimensão política para a análise do conhecimento jornalístico, os critérios de noticiabilidade aparecem como parte da política editorial dos meios de comunicação e dos profissionais que neles trabalham.

\section{JORNALISMO CIENTÍFICO}

De acordo com Thiollent ${ }^{6}$, o jornalismo científico constitui um conjunto de atividades jornalísticas dedicadas a assuntos científicos e direcionadas para o grande público dos não especialistas, por meio de diversas mídias: imprensa, rádio, televisão, jornais especializados, entre outras publicações. Assim, durante o processo de construção do texto de jornalismo científico são utilizados alguns recursos de linguagem, tendo por objetivo aumentar o grau de compreensibilidade do texto a partir da intenção do divulgador em se direcionar para um público de não especialistas.

5. MARCONDES FILHO,

C. $O$ capital da notícia: jornalismo como produção social da segunda natureza. São Paulo: Ática, 1986. p. 12

6. THIOLLENT, M. Jornalismo científico e suas funções no conjunto da comunicação social. Comunicarte, Campinas, $\mathrm{n}$. 2, p. 124,1983

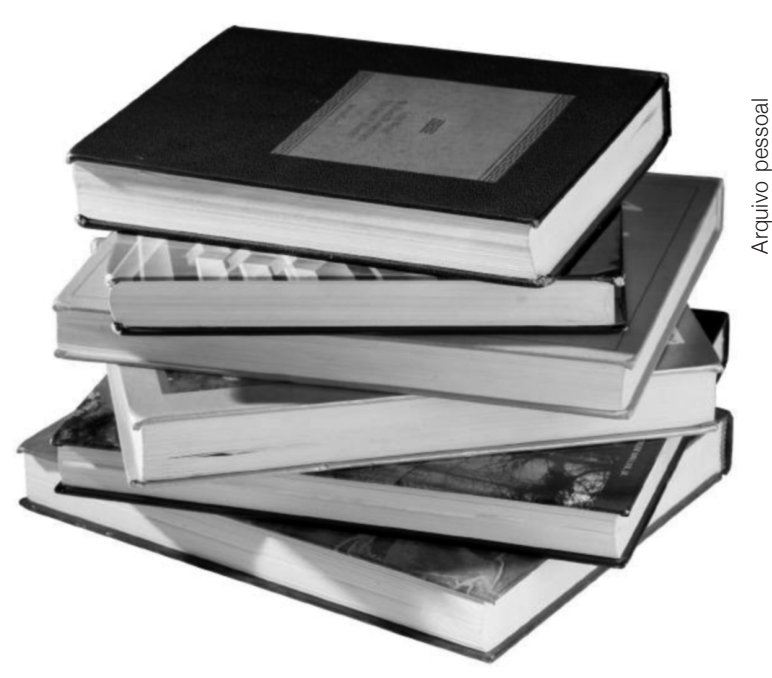

Um elemento apontado por Burkett para aumentar o grau de legibilidade dos textos sobre ciência envolveria a tradução de termos técnicos, sendo que esse vocabulário especializado do campo científico tornaria impossível a sua 
omissão nos textos. Entretanto, para esse autor: "o redator pode definir as palavras do cientista antes ou depois de sua colocação numa frase. Isso exige o planejamento da construção de cada frase de modo que a tradução, explicação ou definição pareça natural e não desajeitada"7. Gomes, após pesquisar as diferenças e semelhanças entre os textos de pesquisadores e de jornalistas publicados na revista Ciência Hoje, observa que na utilização de termos técnicos nos textos escritos por jornalistas, apesar de alguns casos em que as explicações não são satisfatórias, há maior preocupação com o esclarecimento da terminologia empregada ${ }^{8}$.

Outros recursos muito utilizados nos textos de jornalismo científico são as figuras de linguagem, tais como analogias, comparações e metáforas. Para Burkett, no corpo do texto, o jornalista científico pode usar instrumentos para retratar o que seria invisível para o não cientista ou para uma pessoa treinada em ciência, mas numa disciplina diferente, sendo que esses instrumentos incluiriam a metáfora e a analogia. De acordo com esse autor, a metáfora tenta descrever um evento, experiência ou pensamento com base em alguma outra coisa. Já a analogia exige uma comparação entre duas situações nas quais são traçados muitos pontos de similaridade ${ }^{9}$.

\section{PROCEDIMENTOS METODOLÓGICOS}

Uma atividade aqui analisada de leitura de textos sobre física contidos nas revistas Ciência Hoje e Pesquisa Fapesp aconteceu na disciplina Conhecimento em física escolar I, ministrada para alunos ingressantes na licenciatura em física durante o primeiro semestre de 2007, na Universidade Estadual de Campinas. De acordo com a ementa dessa disciplina, nela os licenciandos devem analisar questões específicas do ensino de física e de campos e conhecimentos envolvidos em propostas de soluções para essas questões.

Os alunos receberam textos da seção Física e um questionário com quatro questões versando sobre a leitura dos textos. Após aproximadamente vinte minutos de leitura e elaboração das respostas do questionário, começamos a conversar sobre a leitura dos textos, sendo que essa conversa foi gravada em áudio e vídeo. Neste artigo analisamos algumas respostas dos estudantes ao questionário e falas transcritas do diálogo entre o pesquisador e a sala de aula.

\section{ALGUNS INDÍCIOS DO FUNCIONAMENTO DO DISPOSITIVO ANALÍTICO}

Buscamos nesta seção compreender alguns gestos de interpretação dos licenciandos em física com relação ao dispositivo analítico baseado em algumas características do discurso jornalístico. De imediato notamos algumas interpretações relacionadas à pesquisa desenvolvida no Brasil, que os textos de divulgação da Ciência Hoje e Pesquisa Fapesp abordam de alguma maneira, o que nos faz lembrar o valor-notícia proximidade. Ao ser questionado sobre o que mais lhe
7. BURKETT, W. Jornalismo científico: como escrever sobre ciência, medicina e alta tecnologia para os meios de comunicação. Rio de Janeiro: Forense Universitária, 1990. p. 123

8. GOMES, I. M. A. M. O texto e o discurso na revista Ciência Hoje. In: GOMES, M. C. A.; MELO M. S. S.; CATALDI, C. Gênero discursivo, mídia e identidade. Viçosa: Editora da UFV, 2007.

9. Ibid., p. 126. 
10. PONTE delicada. Pesquisa Fapesp, São Paulo, n. 115 , p. $45,2005$.

11. FIORAVANTI, C. Choque de partículas. Pesquisa Fapesp, São Paulo, n. 120, p. 52-55, 2006.

12. Utilizamos nomes fictícios. chamou a atenção no texto lido, um estudante respondeu: "Que a participação do Brasil seja somente teórica, por não termos recursos para aplicar a teoria na criação de novos produtos".

$\mathrm{O}$ texto $^{10}$ lido por esse licenciando aponta para o fato de o Brasil não conseguir transformar descobertas científicas em inovações tecnológicas, situação levantada pelo físico Adalberto Fazzio. Além de parecer se preocupar com o problema apontado pelo físico, na questão sobre se pediria a alunos do Ensino Médio que lessem o texto, esse licenciando pareceu continuar se detendo em aspectos do desenvolvimento científico nacional: "Sim. [...] para que lessem o final do texto e soubessem, mesmo que superficialmente, a participação do país em novas descobertas".

Nas suas respostas pudemos notar como ele estabeleceu uma interpretação aparentemente com base na ideia do texto de divulgar a participação nacional no desenvolvimento científico, mesmo havendo críticas nessa área.

Outro critério de noticiabilidade que também podemos identificar em uma das respostas dos licenciandos é o valor-notícia inesperado. Na resposta sobre se pediria a alunos de Ensino Médio que lessem o artigo que haviam acabado de ler, pudemos notar na resposta de um licenciando como o fato de a pesquisa constatar um fenômeno já observado descartaria a possibilidade de ele ser trabalhado de alguma maneira no Ensino Médio: "Não. [...] não é muito motivador, pois termina com a constatação do esperado".

Esse licenciando colocou como justificativa para a não utilização do texto ${ }^{11}$ o fato de que ele não seria motivador, pois termina, segundo ele, com a constatação do esperado. Assim, consideramos no posicionamento desfavorável à utilização desse texto no Ensino Médio por esse licenciando o fato de ele considerar relevante que o texto traga assuntos que contrariem ou que estabeleçam algum tipo de controvérsia, ao contrário de assuntos que não provoquem essa ruptura com a normalidade.

Especificamente sobre o jornalismo científico, um aspecto que aparentemente foi notado por alguns estudantes foram os tipos de linguagem adotados pelos textos de divulgação, que, como já mencionamos, têm por finalidade aumentar o grau de compreensibilidade dos assuntos. Após ser instado pelo pesquisador sobre esses aspectos, pudemos notar o posicionamento um tanto cuidadoso de um estudante com respeito à possível adoção de textos dessa natureza no Ensino Médio:

Pesquisador: Gostaria de saber o que vocês acharam da leitura. [...] O que vocês acharam? Leitura técnica demais?

João ${ }^{12}$ : Acho que se fosse trabalhar com os meus alunos teria que dar uma ajuda... em alguns conceitos... mas não é tão absurdo assim. Exige, se fosse uma aula, alguns conceitos básicos, fala de fusão nuclear, núcleos exóticos, isótopos, então teria que explicar isso daí, caso ele não soubesse, mas é interessante.

P.: Teria que ter uma explicação prévia?

João: Ou prévia, ou depois... para ajudar o aluno.

Continuando a conversa, agora sobre os recursos que o divulgador utiliza no seu trabalho de divulgação de tópicos científicos, nesse caso as analogias, 
pudemos notar o posicionamento favorável desse estudante em relação ao uso desses recursos com a finalidade de abranger um público maior que os especialistas:

P.: Então gostaria de saber se seria um problema, essas analogias, esses recursos. João: Eu acho que não. Acho que não podemos ser arrogantes a ponto de escrever um texto que só os físicos entendam.

José: Depende do público que você quer atingir.

João: Exatamente. Acho que não prejudica de forma alguma. Mais didático, mais prazeroso de ler.

Consideramos, em sua interpretação, como ele demonstrou certa preocupação com a linguagem dos textos e a abrangência do público-alvo, além dos especialistas, quando se posicionou de maneira contrária à escrita de "um texto que só os físicos entendam". Notamos em outro licenciando considerações sobre o uso de terminologia específica do campo científico, bem como seu posicionamento em como trabalhar com esse aspecto nos textos de divulgação:

P.: Então o comunicador teria que acertar na linguagem?

Carlos: Linguagem, por exemplo, o que aborda, vamos supor, colisões de partículas, aí fala de partículas elementares, aí coloca ali entre aspas o que significa partículas elementares para ser bem didático. Agora, se pegar um texto de Scientific American em relação a elas aí, é bem direto... já fala direto sem...

Consideramos em seu posicionamento a mesma sugestão de Burkett ${ }^{13}$, que o redator pode definir as palavras do cientista antes ou depois de sua colocação numa frase, como o recurso das aspas mencionado pelo licenciando. Em outro licenciando também notamos a preocupação com o léxico específico da ciência:

Lucas: [...] O texto que eu li aqui, eu não teria curiosidade nenhuma de ler o que está por trás disso.

Pesquisador: Que texto você leu?

Lucas: Radiação sobre medida. Um que ele muda de cor quando passa uma radiação. [...] Ele fala que o líquido é polidoismetoxilcincoetil, sei lá, aí fica complicado isso daqui, agora alguém... Meu pai de novo para ler isso daqui, está me xingando...

Os gestos de interpretação desse licenciando pareceram reforçar as considerações de Gomes ${ }^{14}$, quando esta autora notou que o uso de termos especializados que ainda não fazem parte do vocabulário corrente de não especialistas, sem qualquer esclarecimento, parecem ser determinados pela idealização de leitores especialistas. Ao afirmar que não teria nenhum interesse de ler mais coisas a respeito do assunto, esse licenciando pareceu se preocupar com o uso de léxicos próprios ao campo científico, sem esclarecimentos, nos textos de divulgação e como eles poderiam dificultar a leitura de pessoas não familiarizadas com a ciência.

Os posicionamentos de João, Carlos e Lucas após a leitura de textos de divulgação da física nas revistas Ciência Hoje e Pesquisa Fapesp aparentemente nos indicam a dificuldade quando pensamos na circulação de assuntos científicos em um âmbito mais amplo do que o restrito ao campo científico, sendo que
13. BURKETT, Jornalismo científico, cit.

14. GOMES, O texto e o discurso na revista Ciência Hoje, cit. 
comunicação \& educação • Ano XVI • número 1 • jan/jun 2011

eles pareceram questionar, portanto, esse conceito basilar da divulgação científica, que é promover determinada ciência para um público não especializado.

\section{CONSIDERAÇÕES FINAIS}

Vimos neste artigo a relevância da construção de um dispositivo analítico baseado em noções do jornalismo e do jornalismo científico, quando nos propomos a investigar aspectos da leitura de textos dessa natureza. Também expusemos alguns elementos desse dispositivo, quando este foi colocado em funcionamento em uma atividade de leitura com estudantes do curso de licenciatura em física. Após abordarmos algumas relações entre um dispositivo analítico baseado em aspectos do jornalismo - composto de noções de critérios de noticiabilidade e jornalismo científico - e gestos de interpretação de estudantes de licenciatura em física, justificamos o trabalho com um dispositivo analítico que contemple condições constitutivas da produção dos textos de divulgação científica nos meios de comunicação, para a investigação de aspectos concernentes à leitura de tais textos.

\section{REFERÊNCIAS BIBLIOGRÁFICAS}

ALMEIDA, M. J. P. M. de. Discursos da ciência e da escola: ideologia e leituras possíveis. Campinas: Mercado de Letras, 2004.

BURKETT, W. Jornalismo científico: como escrever sobre ciência, medicina e alta tecnologia para os meios de comunicação. Rio de Janeiro: Forense Universitária, 1990 .

FIORAVANTI, C. Choque de partículas. Pesquisa Fapesp, São Paulo, n. 120, 2006.

GOMES, I. M. A. M. O texto e o discurso na revista Ciência Hoje. In: GOMES, M. C. A.; MELO, M. S. S.; CATALDI, C. Gênero discursivo, mídia e identidade. Viçosa: Editora da UFV, 2007.

MARCONDES FILHO, C. O capital da notícia: jornalismo como produção social da segunda natureza. São Paulo: Ática, 1986.

ORLANDI, E. P. Análise de discurso: princípios e procedimentos. Campinas: Pontes, 2005.

PONTE delicada. Pesquisa Fapesp, São Paulo, n. 115, 2005.

THIOLLENT, M.Jornalismo científico e suas funções no conjunto da comunicação social. Comunicarte, Campinas, n. 2, 1983.

TRAQUINA, N. Teorias do jornalismo: a tribo jornalística - uma comunidade interpretativa transnacional. Florianópolis: Insular, 2005.

WOLF, M. Teorias da comunicação. Lisboa: Presença, 2006. 